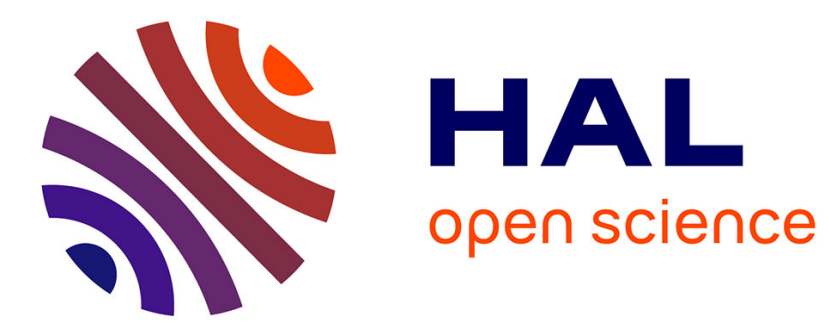

\title{
Microtexture of Ti6Al4V Obtained by Direct Energy Deposition (DED) Process
}

\author{
Laurent Weiss, Philippe Acquier, Lionel Germain, Eric Fleury
}

\section{To cite this version:}

Laurent Weiss, Philippe Acquier, Lionel Germain, Eric Fleury. Microtexture of Ti6Al4V Obtained by Direct Energy Deposition (DED) Process. 13th World Conference on Titanium, 2015, San Diego, United States. pp.1305-1310, 10.1002/9781119296126.ch221 . hal-02455035

\section{HAL Id: hal-02455035 \\ https://hal.science/hal-02455035}

Submitted on 25 Jan 2020

HAL is a multi-disciplinary open access archive for the deposit and dissemination of scientific research documents, whether they are published or not. The documents may come from teaching and research institutions in France or abroad, or from public or private research centers.
L'archive ouverte pluridisciplinaire HAL, est destinée au dépôt et à la diffusion de documents scientifiques de niveau recherche, publiés ou non, émanant des établissements d'enseignement et de recherche français ou étrangers, des laboratoires publics ou privés. 


\title{
MICROTEXTURE OF TI6AI4V OBTAINED BY DIRECT ENERGY DEPOSITION (DED) PROCESS
}

\author{
Laurent Weiss ${ }^{1,2}$, Philippe Acquier ${ }^{3}$, Lionel Germain ${ }^{1,2}$, Eric Fleury ${ }^{1,2}$ \\ ${ }^{1}$ LEM3, Université de Lorraine, Ile du Saulcy, 57000 Metz, France \\ ${ }^{2}$ Laboratory of Excellence for Design of Alloy Metals for Low-mass Structures ('DAMAS' Labex), Université de Lorraine, France \\ ${ }^{3}$ IREPA LASER, Boulevard Gonthier d'Andernach, Parc d'Innovation, 67400 Illkirch, France
}

Keywords: Laser Metal Deposition; additive manufacturing; TA6V; texture

\begin{abstract}
The microstructure of bulk samples prepared by CLADR additive manufacturing of Ti-6Al-4V (Ti64) powder have been investigated by means of SEM and phase reconstruction. The CLADR technique (laser blown powder processing) developed at IREPA LASER provides very high cooling rate promoting the formation of the martensitic $\alpha^{\prime}$ phase in the form of thin needles. Using Merengue 2 software developed at LEM3, the analysis of the martensitic phase orientation by EBSD enables the reconstruction of the primary $\beta$-phase that formed at high temperature. Microstructural observations performed at various locations within the samples revealed marked heterogeneities in the microstructure. After the first deposited layer characterized by fine and equiaxed $\beta$ grains, the $\beta$ grains located in the central region of the samples tend to grow in a direction perpendicular to the deposited layer plan with a coarse columnar structure. By opposition, the grains on the sample side were found to grow at angle of about $60^{\circ}$ from the deposited layer plan. The main difference with others additive manufacturing techniques is that, only a weak crystallographic $\beta$ texture was detected in these samples prepared by CLADR.
\end{abstract}

\section{Introduction}

Since a decade, the understanding on laser rapid manufacturing technologies has rapidly increased and the developers found applications in various industrial sectors for parts manufacturing or repairing. IREPA LASER has developed its own specific tools for the manufacturing of meso-scale and macro-scale metallic and functional 3D parts from CAD files $[1,2]$. This process, named CLADR (Construction Laser Additive Direct), is based on laser cladding, and involves the deposition of melted powders into a melt pool for 3D component manufacturing. The process parameters in additive manufacturing are numerous and the general properties (geometry, mechanical) of the manufactured parts are directly related to the operating conditions and to the materials used. For example, the properties of common AISI 316L samples made by LMD (Laser Metal Deposition) have been studied and are well understood [3, 4], but the influence of process parameters on the characteristics of the manufactured samples, i.e. microstructure, is not clearly established.
The microstructure description and evolution of Ti-6Al-4V titanium alloy have been investigated for different additive manufacturing techniques, which are mostly powder bed processes techniques: Electron Beam Melting (EBM) [5, 6, 7], Selective Laser Melting [8, 9, 10], or wire feed technique [11, 12]. To the authors' knowledge, results of study on powder blown processing applied to Ti-6Al-4V alloy have not been reported yet. This paper aims at investigating the microstructure and texture obtained by powder blown additive manufacturing process and at underlining the main differences with other additive manufacturing technologies.

\section{Material and experimental setup}

The laser deposition tests were carried out on a 5 axis LMD machine designed by IREPA LASER (fig. 1 (a)). The substrate was a Ti6Al4V plate with $5 \mathrm{~mm}$ thickness. The process developed by IREPA LASER is a blown powder additive manufacturing process, called CLADß process, with a laser as a heating source. In this process, a material in a powder form is injected in a coaxial nozzle (US Patent $n^{\circ}$ 5418350). The powder is carried by a transport gas. At the output of the nozzle, the powder jet is shaped by a secondary gas (fig. 1(b)) in order to concentrate the powder density. The powder is then heated and melted by a laser source before to be deposited on a substrate. The addition of deposited layers creates the manufactured object.

This machine is equipped with a $500 \mathrm{~W}$ diode laser $(200 \mu \mathrm{m}$ diameter and $1070 \mathrm{~nm}$ wavelength) from IPG LASER. This machine is equipped with 5 axis, with travels of X1500 $\times$ Y $800 \times$ $\mathrm{Z} 800 \mathrm{~mm}$ for the linear axes, and a swiveling (B) and rotating (C) movement for the part (Fig. 1a). In this configuration, the nozzle works always vertically, because gravity affects the powder jet stream. Two nozzles are integrated into this machine, and work alternatively for the manufacturing of the parts. The first nozzle (called macroCLAD 10Vx) makes deposition tracks with a width in the range of 1-1.2 $\mathrm{mm}$, and the second nozzle (called macroCLAD 24Vx), equipped with a different optical system, makes tracks width in the range of 2-2.4 mm. The machine is equipped with a gas enclosure, with a volume of $12 \mathrm{~m} 3$ specially adapted for the manufacturing of Ti alloys parts. During the process, the $\mathrm{O}_{2}$ concentration is less than 20 ppm and $\mathrm{H}_{2} \mathrm{O}$ concentration less than 100 ppm. 


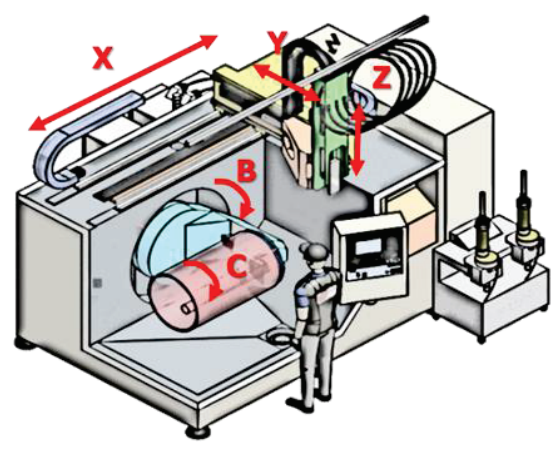

(a)

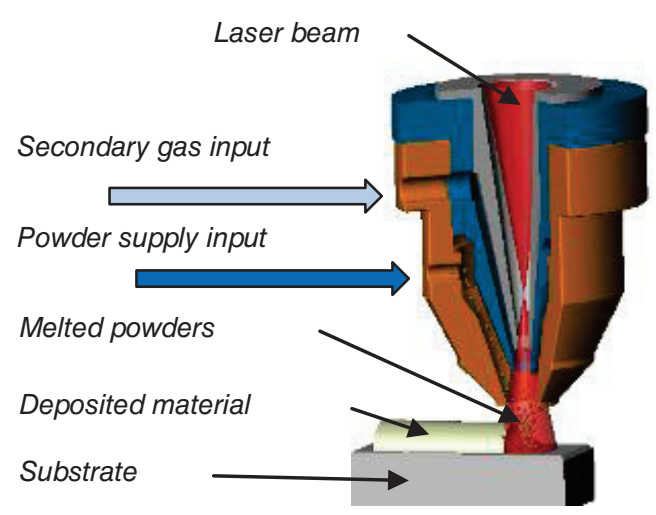

(b)

Figure 1: (a) the 5 axis CNC workstation (b) the coaxial laser cladding nozzle patented by IREPA LASER

The titanium powder used for this study was plasma atomized Ti6Al4V grade 23 from AP\&C with a 45-90 $\mu$ m diameter. A cube with $20 \mathrm{~mm}$ edge length has been built. The distance between the nozzle and the deposited track was $35 \mathrm{~mm}$. The sample has been made under controlled atmosphere with less than $20 \mathrm{ppm} \mathrm{O}_{2}$ and less than 100 ppm $\mathrm{H}_{2} \mathrm{O}$. The macroCLAD 10Vx nozzle was used for part manufacturing. The laser power was $425 \mathrm{~W}$, the scan speed was $2000 \mathrm{~mm} / \mathrm{min}$ and the powder flow was $2.1 \mathrm{~g} / \mathrm{min}$. The resulting track dimensions were $0.94 \mathrm{~mm}$ for the track width and $0.27 \mathrm{~mm}$ for the track height.

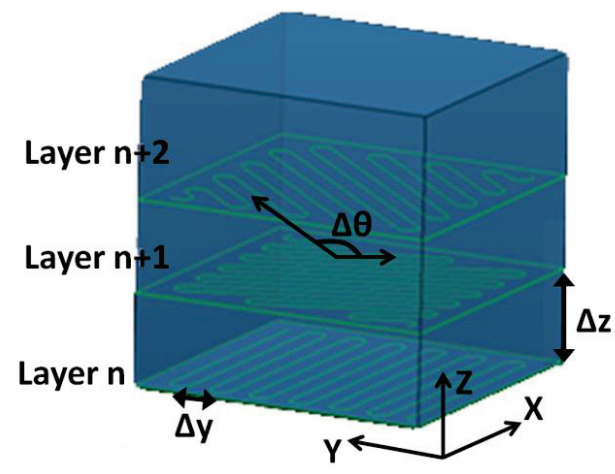

Figure 2: Building strategy

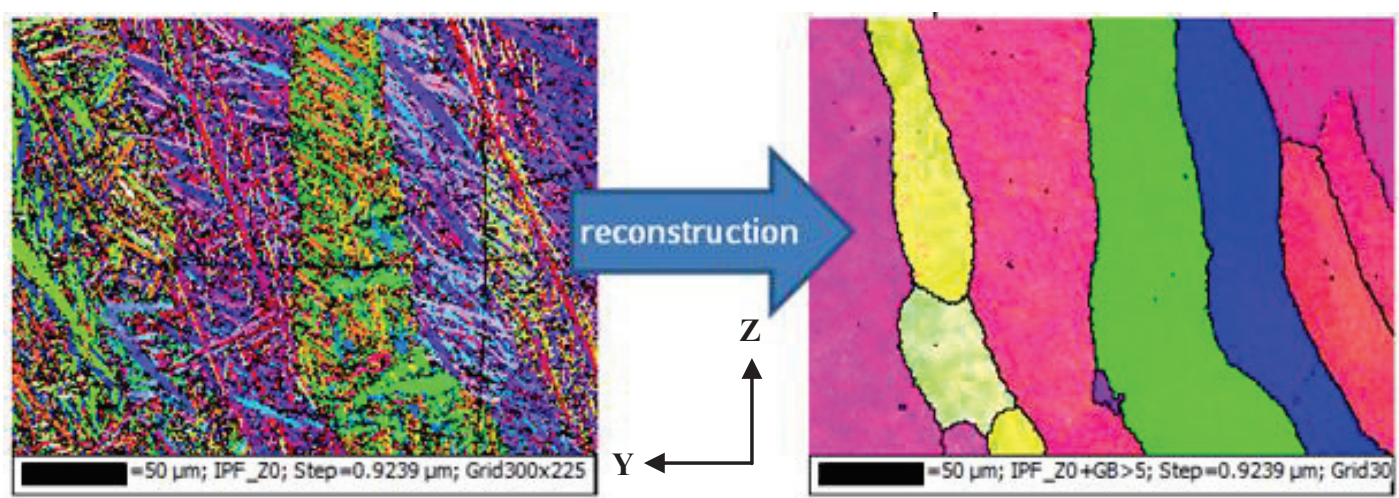

Figure 3: Example of a picture from the center of the $Y Z$ sample face before and after reconstruction

The construction strategy consisted of a filling of the inside with parallel tracks with an overlap of $30 \%$ (i.e $\Delta y=0.7 \mathrm{~mm}$ ). Finally, around each layer a contour track is deposited (fig. 2). The height between each layer, $\Delta \mathrm{z}$, was the height of one track: $0.27 \mathrm{~mm}$. The track deposition direction between two consecutive layers was rotated by $\Delta \theta=113^{\circ}$ in order to reduce the content of residual stresses.

The macrographic analysis was performed with an optical microscope Olympus BX61 and reconstruction multimaping with Stream Motion software. The microscopic images were taken on two different JEOL scanning electron microscopes: a JSM-6490 (with a W-gun) and a JSM-6500F (with a field emission gun). Grain orientations were determined by electron back-scattered diffraction (EBSD), using AZtech (Oxford Instruments, HKL Technology) for data acquisition. The reconstructions of the primary $\beta$ grains were performed with the Merengue 2 software developed by the LEM3 (Fig. 3). The reconstruction procedure is similar to that described by Germain and coworkers [13] and is performed in three steps. In a first step, crystallographic domains (grains) are identified using an Anti-Leak Grain detection [14] with $\omega_{0}=3^{\circ}$ and $\omega_{1}=0^{\circ}$. In a second step, neighboring domains related by the Burgers orientation relationship (with a $3^{\circ}$ tolerance) to a common parent orientation are sought. Those which satisfy some quality criteria (set by trial and error) are called fragments and their parent orientations are then known. Starting from fragments, Merengue 2 gathers all domains related 
by the Burgers relationship (within a tolerance of $4^{\circ}$ ) to the same parent. This last step called "enlargement" allows the determination of the parents orientations of the remaining domains.

\section{Experimental results}

The sample in the as produced condition is shown Fig.4 a. It has then been cut for metallographic observation (Fig. 4 b) both in longitudinal and transversal directions.

On the macrograph (Fig.5), a very coarse structure can be observed. It corresponds to the columnar $\beta$ grains which are up to several millimeters long. At a higher magnification, the martensite needles can be observed in the primary $\beta$ grains. The boundary between the substrate and the deposited layers is clearly distinguishable. This is due to the brutal change in microstructure: the micro-grains of the rolled plate suddenly grow at the border which delimits the molten zone at the bottom of the image. It is also possible to see horizontal bands corresponding to deposited layers with a $270 \mu \mathrm{m}$ thickness.

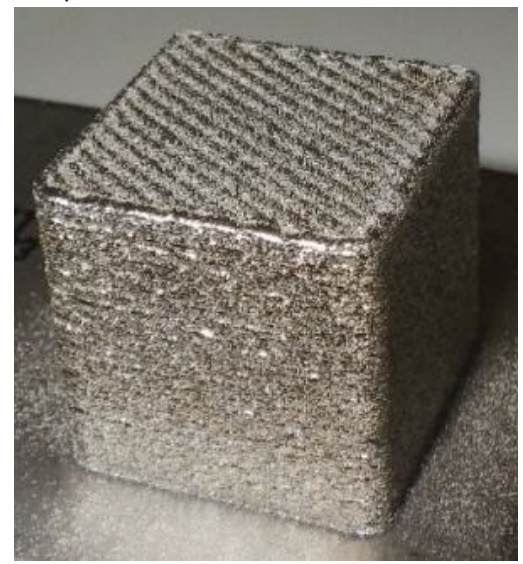

a

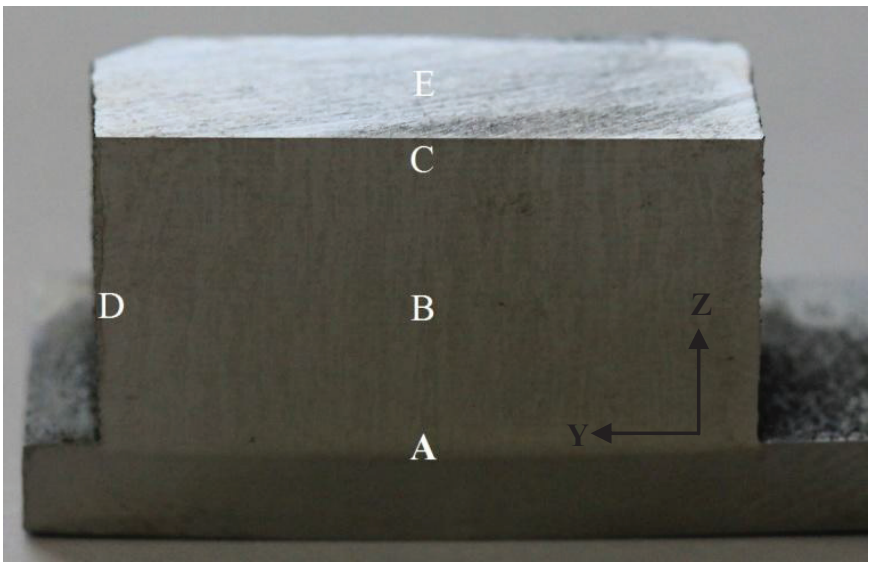

b

Figure 4: a. Sample as produced. $b$. Center of the sample after cutting with the letters corresponding to the analyzed zone (A=Bottom; $B=$ Center $; C=$ Top $; D=$ Side $; E=X Y$ face)

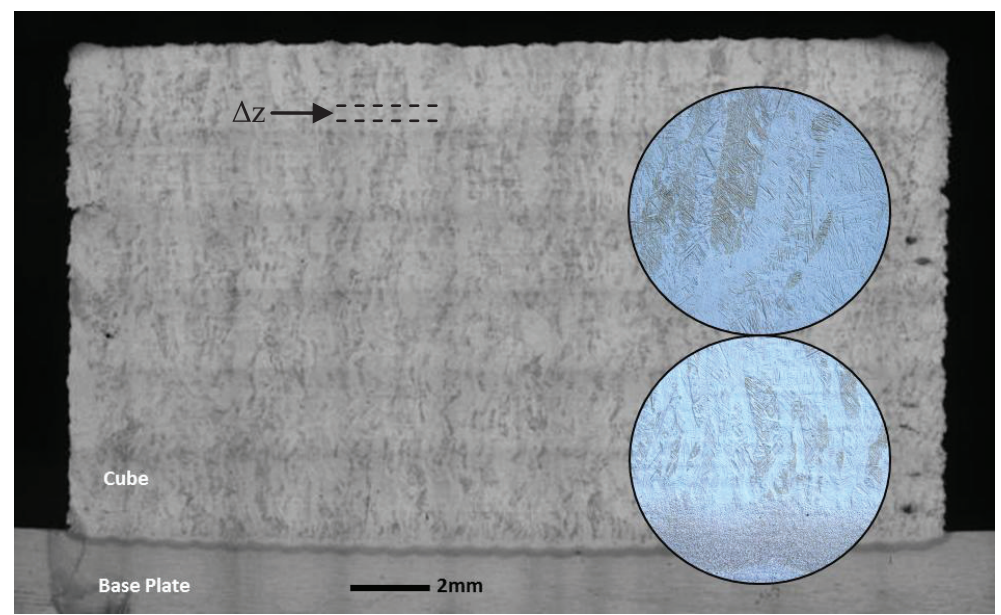

Figure 5: Multimapping picture of XZface in the center of the sample. The columnar grains can be seen in the enlargements 


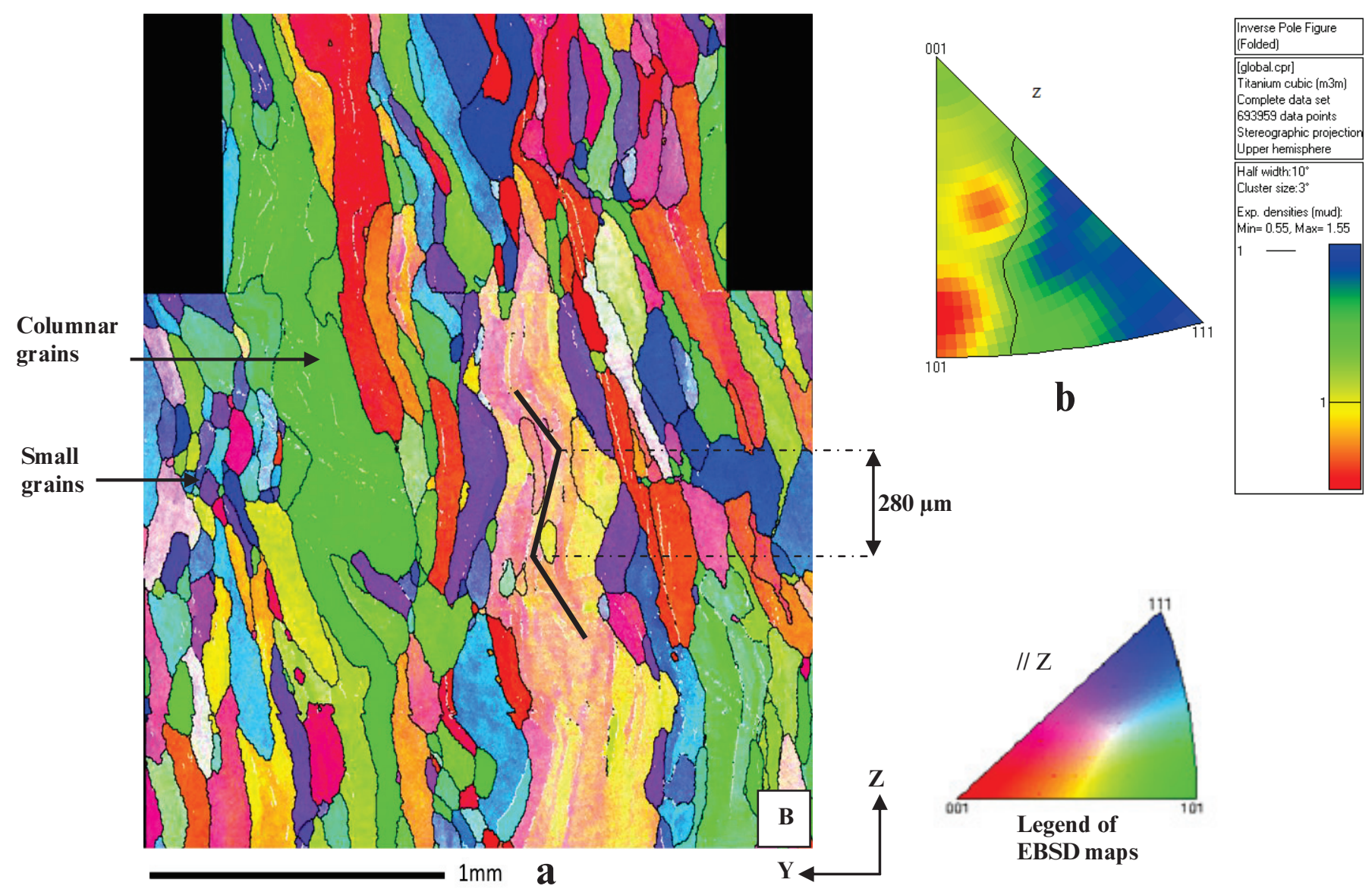

Figure 6: a. EBSD Map corresponding to the area B as shown in the fig. $4 b$ (grain boundaries: black $>10^{\circ}$; white $>6^{\circ}$ ) and $b$. Inverse Pole Figure (IPF) adds up all maps of this paper (150 grains).
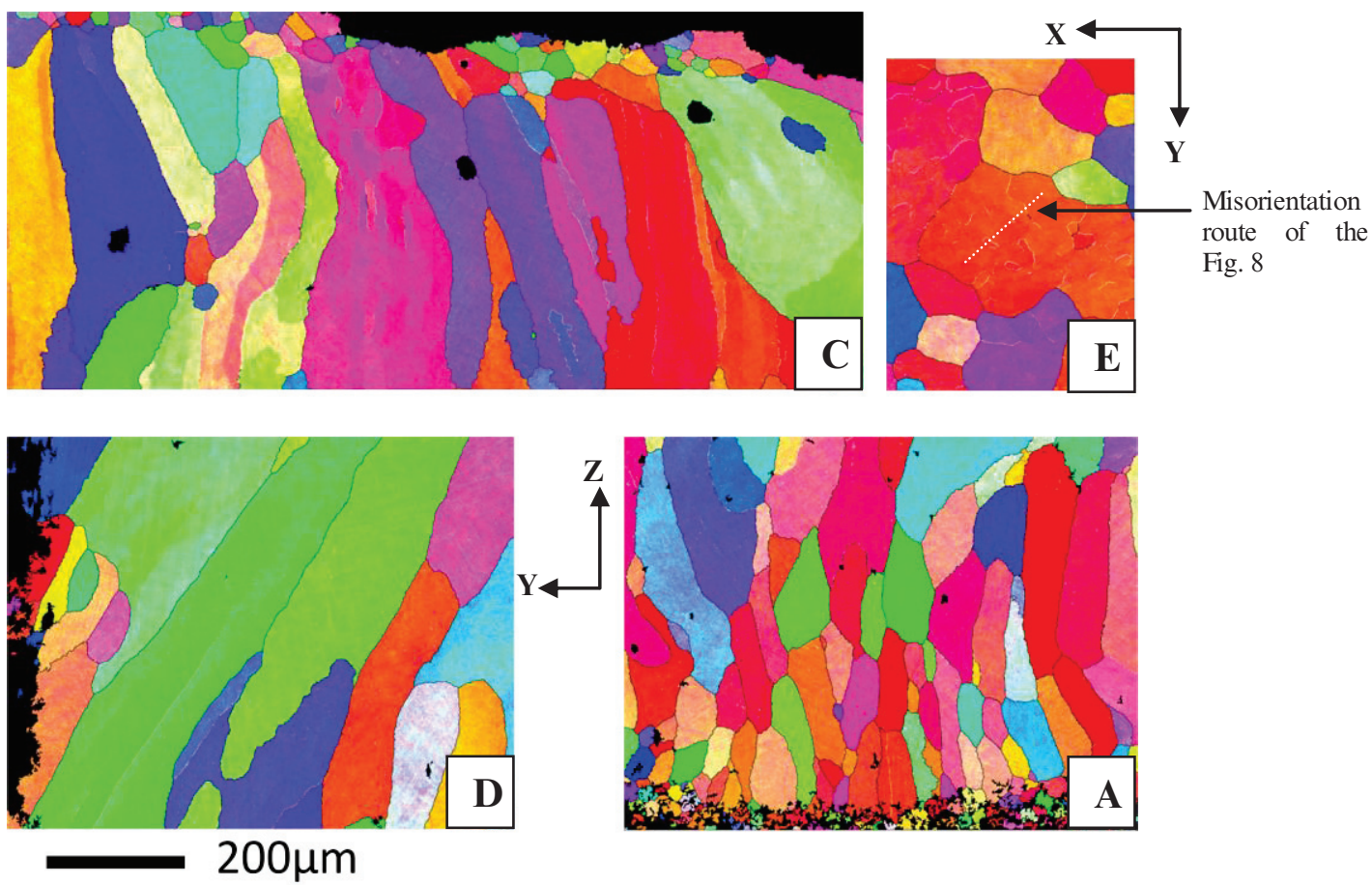

Figure 7 : EBSD Map corresponding to the areas A, C, D and E as shown in the fig.4. The E map is in the XYplan. The legend is previously given in the Fig. 6 


\section{Discussion}

In contrary to the EBM method which gives a fine $\alpha$ structure, the final structure of the sample was composed of $\alpha^{\prime}$ martensite needles like in parts manufactured by SLM (Selective Laser Melting) [8]. This is due, in the case of the CLAD method, to rapid cooling caused by the argon gas, which continuously circulates around the melted powder. This martensitic structure is homogeneous throughout the piece, in the center as at the edges.

As mentioned earlier, several authors have been observed the formation of columnar grains in Ti-6Al-4V fabricated by additive deposition. This grain morphology is due to the re-melting of the previously deposited layers as well as the thermal gradients [5]. As the last layer does not undergo this series of thermal processing, it produces a small grains structure corresponding to the powder melted then rapidly solidified.

In the central area, the columnar grains present a herringbone pattern. It is interesting noting that the distance between each turn is equal to the thickness of a deposited layer (Fig. 6). This shows that the grain shape is strongly dependent on the deposition strategy. This relation is the subject of an on-going work. CLAD method gives a high heterogeneity in terms of $\beta$ microstructure and texture for the primary beta grains. Indeed, usually in additive deposition, the grains have their $<100>$ direction perpendicular to the deposition direction. This particular orientation due to thermal gradients, is found in all additive manufacturing process and has been observed by all the authors mentioned above. In the case of the CLAD method and with the construction strategy of rotating tracks by $113^{\circ}$ between each layer, the measures show that this process produces a weak texture (IPF Fig.6). Besides, beta grains exhibit substructures which misorientation profile is shown in Figure 8.

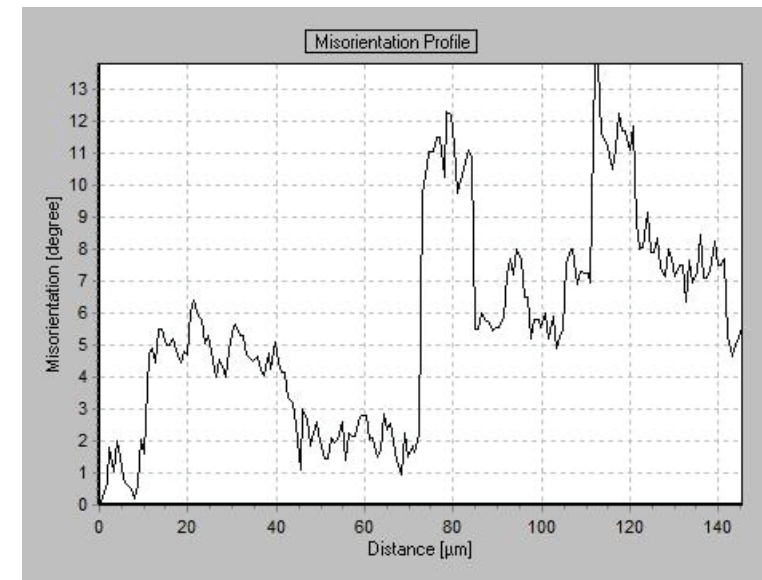

Figure 8: Misorientation profile into a columnar grain (the route is visible in the Fig. 7E)

However, from the microstructure point of view, small grains are trapped in the matrix formed by the columnar grains which is a new result compared to the studies undertaken so far with other techniques such as bed powder or the electron beam. Due to their size and their shape (Fig 6), these small grains could be either unmelted or partially melted powder particles. Further testing are underway to confirm these hypotheses.

The structure inclined at about $60^{\circ}$ located around the edges is due to the direction of thermal gradients as explained by Thijs et al. and is the result of the contour deposition as shown by Antonysamy and colleagues [6] for Ti6Al4V produced by EBM.

\section{Conclusion}

CLAD process was used to fabricate Ti-6Al-4V pieces. Rapid cooling of the molten zone results in a $\beta \rightarrow \alpha^{\prime}$ martensite transformation throughout the sample.

Reconstruction of the primary $\beta$ grains shows a heterogeneous structure comprising central columnar grains parallel to the growth axis with an herringbone pattern. These primary $\beta$ grains measures up to several millimeters in the building direction. Some small grains, which could be unmelted or partially melted powder particles, are found on the sample edges and are trapped between the previously described grains.

Unlike other additive manufacturing techniques such as EBM or SLM in which the axis $<100>\beta$ is parallel to the sample $\mathrm{z}$ axis (build direction), the CLAD ${ }^{\circledR}$ process does not reveal any significant texture. To explain this phenomenon, more information is needed and it is considered to correlate the deposition strategy with primary formed $\beta$-grain shape and the mechanical properties of the pieces in future studies.

\section{References}

1. Pierre-Alain Vetter, Study of the interaction between an high power laser beam and powder flow - Application to laser cladding, $\mathrm{PhD}$ thesis, Université de Strasbourg, France, 1997 (In french)

2. Simon Sankaré, Development of a rapid manufacturing process of mechanical components in titanium alloys by laser microcladding, $\mathrm{PhD}$ thesis, University of Strasbourg, France, 2007 (In french)

3. Jyotsna Dutta Majumdar et al, Microstructure characterization and process optimization of laser assisted rapid manufacturing of 316L stainless steel, Applied Surface Science, 247, (2005), 320327.

4. Rui Vilar, Laser cladding, The International journal of powder metallurgy, 37, (2001), 31-48.

5. Sinan Al-Bermani et al, The Origin of Microstructural Diversity, Texture, and Mechanical Properties in Electron Beam Melted Ti-6Al-4V. Metallurgical and Materials Transactions A 41 (13), (2010), 3422- 34.

6. Alphons Anandaraj Antonysamy, J. Meyer, and Philip Prangnell. Effect of build geometry on the $\beta$-grain structure and texture in additive manufacture of Ti6Al4V by selective electron beam melting, Materials Characterization 84 (2013), 153-168.

7. Lawrence Murr et al., Microstructures and mechanical properties of electron beam-rapid manufactured Ti-6Al-4V biomedical prototypes compared to wrought $\mathrm{Ti}-6 \mathrm{Al}-4 \mathrm{~V}$, Materials Characterization 60 (2), (2009) 96- 105. 
8. Lore Thijs et al., A study of the microstructural evolution during selective laser melting of Ti-6Al-4V, Acta Materialia 58 (9), (2010) 3303- 12.

9. Alphons Anandaraj Antonysamy, Microstructure, Texture and Mechanical Property Evolution during Additive Manufacturing of Ti6Al4V Alloy for Aerospace Applications, $\mathrm{PhD}$ thesis. University of Manchester, UK, 2012.

10. Marco Simonelli, Yau Yau Tse, et Christofer Tuck, Further Understanding of Ti6Al4V Selective Laser Melting Using Texture Analysis, In Proceedings of 23rd Annual International Solid Freeform Fabrication Symposium, Austin, TX (2012)

11. Bernd Baufeld, Erhard Brandl and Omer van der Biest, Wire based additive layer manufacturing: Comparison of microstructure and mechanical properties of $\mathrm{Ti}-6 \mathrm{Al}-4 \mathrm{~V}$ components fabricated by laser-beam deposition and shaped metal deposition, Journal of Materials Processing Technology 211 (6), (2011) 114658.

12. Erhard Brandl, Achim Schoberth and Christoph Leyens, Morphology, microstructure, and hardness of titanium (Ti-6Al4V) blocks deposited by wire-feed additive layer manufacturing (ALM), Materials Science and Engineering: A 532 (2012) 295307.

13. Lionel Germain et al, An advanced approach to reconstructing parent orientation maps in the case of approximate orientation relations: Application to steels. Acta Materialia 60, (2012) 45514562 .

14. Lionel Germain et al, Identification of sub-grains and low angle boundaries beyond the angular resolution of EBSD maps, Material Characterization 98 (2014) 66-72. 